The application of business risk audit methodology within non-Big-4 firms

\author{
Imad Kutum \\ Kutum \& Associates Inc \\ Ian Fraser \\ Stirling University, UK \\ \& \\ Khaled Hussainey \\ Plymouth University, UK
}

Accepted for Publication

Journal of Financial Reporting and Accounting

Correspondence should be addressed to:

Dr. Imad Kutum

Kutum \& Associates Inc

A1-5659 McAdam Road

Mississauga, ON L4Z 1N9

Tel: 905-330-6826

Fax: 905-276-2003

www.kutum.com 


\section{The Application of Business Risk Audit Methodology within Non-Big-4 Firms}

\section{Introduction}

2.

Following the accounting scandals in the 1990s, how auditors conduct audits has become an important issue. However, well before these scandals, an important issue for auditors was their concern over the methodologies used to conduct audits and to identify the risks for clients. Over several decades, the popularity of different methodologies changed as concerns about auditors evolved in terms of how audits were conducted and what information was sought during audits. The Business Risk Audit methodology (hereinafter referred to as "BRA") has received much attention within the auditing industry over the past two decades because it is believed to provide technical advantages to auditors when researching and identifying risk in companies' operations (Bell et al., 1997; Brands, 1998; Lemon et al., 2000; Winograd et al., 2000; Knechel, 2001; Bell and Solomon, 2002).

It is important to understand how BRA is used in different countries and to address, also, cultural differences and to determine how this affects the application of BRA. Simply to present information and opinions about BRA without taking into account the country of origin is to ignore potentially much information about how auditors have implemented BRA and how they view its future use. This research examines the auditors' views on the use of BRA in the UK, USA and Canada. Focusing on these three countries enables a comparison to be made of how auditors use BRA, and how they feel about the changes which may be needed to make BRA more appropriate for their clients.

Another issue, often ignored in academic literature, is the actions and operations of small and medium-sized auditing firms; this is because much of the literature focused on the Big-4 audit firms. This research considers BRA from the standpoint of small and medium-sized auditing firms, and specifically how they have implemented BRA and how they view its future as an audit methodology.

Therefore, this study's objective is to examine BRA from the standpoint of small and medium-sized auditing firms in the UK, USA and Canada. It seeks to improve understanding of how BRA was implemented in small and medium-sized enterprises (SMEs) in the UK, USA and Canada and the similarities or differences in implementation are each of the three countries. The researcher chose these particular countries because they dominate the global auditing industry and 
are considered to be the most influential in setting auditing rules and standards (Campbell, 2008). All three countries have specific governing bodies which are responsible for researching, identifying and implementing rules used by all auditors. The presence of governing bodies, such as the American Institute of Certified Public Accountants in the USA, the Auditing and Assurance Standards Board in Canada and the International Auditing and Assurance Standards Board in the UK, stablished standards in all three countries (rather than these being done by government bodies or entities). This is important because it demonstrates that, whilst their memberships consist of more than auditors, it is ultimately the professional auditors in the UK, USA, and Canada who decide on and implement auditing standards (Ball, 2006).

This research adds to literature on the practices and attitudes of small and medium-sized auditing firms in the UK, USA and Canada towards the use of BRA. This is one of the few studies to examine BRA in SMEs. In addition, this is the first study to investigate the motivation of small and medium-sized auditing firms to apply BRA and the first study to offer a comparative analysis of BRA in relation to SMEs across the UK, USA and Canada.

Previous research on the BRA approach focused mainly on the big-4 firms practices (Eilifsen et al., 2001; Lemon et al., 2000). This research adds to the literature on the practices and attitudes of small and medium-sized auditing firms in the UK, USA and Canada towards the use of BRA. This is one of the few studies to examine BRA in SMEs. In addition, this is the first study to investigate the motivation of small and medium-sized auditing firms to apply BRA and to offer a comparative analysis of BRA in relation to SMEs across the UK, USA and Canada.

This research contributes to filling the gap between the theoretical auditing standards and the practical audit whereby, despite their significant role in providing the assurance services to clients in all countries, little research has been done to explore the non-big-4 practices.

\section{Literature Review}

\subsection{Implementation of BRA}

The first generation of audit methodologies featured detailed inspections of financial statements and records; during the 1960s and 1970s, this moved gradually to sampling-based auditing. The third generation, audit risk methodology, was used widely in the early 1980s and the fourth 
generation, BRA, began to be used between 1995 and early 2000. All Big-4 firms adopted BRA under different names (Winograd et al., 2000; Curtis and Turley, 2007).

Other big audit firms rushed to implement the new concept and claimed to introduce it in response to their clients' needs and in order to add value to their services. Elliot (1996), a leading KMPG partner, suggested that auditing was "reborn" at this time. For audit clients requesting an audit, KPMG promised, also, a new era which went beyond numbers. Changes in the amount of information and the way in which it can be obtained complicates the relevance of auditors and the performance of their duties in changing business climates. For example, Abdel-Khalik (1998) stated that US firms used typically the audit risk model explained earlier. However, firms in Canada and parts of Europe focus on a model of BRA which relies more on subjective probability, namely, whereby auditors examine the history of actions taken by company leaders, and the records of past material misstatements in order to determine the risk of material misstatements arising in the future.

Researchers (Curtis and Turley, 2007; Lemon et al., 2000; Knechel, 2007) noted that, in order to perform successful audits, the use of BRA required individual auditors to have a greater level of knowledge and additional skills. In the traditional approach, auditors needed only to examine financial data and look for areas in financial transactions or accounting systems where mistakes or misstatements could occur. Within BRA, auditors must examine information from a wide variety of sources and be concerned with a range of facts and figures. As Knechel (2007) stated, it should not be a major surprise that sometimes the information, gathered in BRA, can be conflicting in nature and in terms of what it says about a company and its financial reporting risks. This means that auditors must have or develop the skills to make judgements based on evidence and information which may appear uncertain. Also, auditors must know when the uncertainties are truly too large and make decisions as to when more information and data are needed, or if enough investigation has occurred to make a decision.

Furthermore, regarding senior members and partners of auditing firms, Curtis and Turley (2007) suggested that there were problems in how these auditors actually used BRA in relation to information contained in financial statements. Their interviews with these auditors identified disagreements in the larger auditing process about where to examine business risks and where to assess only information contained in financial statements. Some senior auditors and partners were concerned that assessing business risks too early in the audit process distracted auditors from 
examining financial records for material misstatements. Lemon et al. (2000) provided a graphical approach to the delivery of BRA with the move from audit risk to business risk along the $\mathrm{x}$ axis, and financial-statement attention and valued-added client services on the y axis. In this regard, audit risk is aligned more with attention to financial statements and business risks are connected more to the value-added services provided to clients. Robson et al. (2007) explained that BRA required other changes in thinking about the audit process; one of which is the very notion of when risk assessment should take place. They stated that, in the older paradigm of auditing, risk assessment took place periodically; however, the new view of BRA entails thinking of risk assessment as a continuous process rather than something which, for example, occurs, once a year.

Robson et al. (2007) explained that the ability of auditing firms to navigate and implement BRA successfully was important in terms of their legitimacy in the financial world. This is especially so amongst firms which pay large fees to hire auditing firms on an ongoing basis to conduct audits, and to provide consulting services. In fact, Curtis and Turley (2007) stated that the development and implementation of BRA had to be instigated by the concern of many auditing firms that companies wanted to avoid increasing fees charged by firm partners without obtaining some added value in return. Furthermore, rather than adding more tasks, BRA has shifted merely the work for which auditing firms charge, from auditing to consulting,. Robson et al. (2007) showed that, in 1975, the USA's Big-8 auditing firms generated $71 \%$ of their total revenue from auditing and another $12 \%$ from consulting. By 1990, only $49 \%$ of total revenues were obtained from audit work and $26 \%$ from consulting. BRA has blurred the lines between auditing firms performing genuine company audits in order to ensure that material misstatements of financial information have not taken place, and performing consulting work in order to identify and help to keep business risks under control for their clients. Knechel (2007) explained that a new challenge for auditing firms was the separation of auditing from consulting and the avoidance of any appearance that the two duties were the same.

Robson et al. (2007) stated that, in reality, the use of BRA really entailed a merger of prevailing attitudes in the current business climate and the current prevailing technology. The authors explained that, even as the need for auditors shifted and as businesses wanted more out of auditors and auditing firms, auditors were trying to combine the role of adviser with that of financial auditor in order to keep the role of the auditor and the professional status of the job and the auditing firm at a higher level. Robson et al. (2007) believed, also, that the emergence of BRA 
amongst auditing firms had not been studied fully in order to determine its outcome. They stated that, in order to ensure better understanding within the industry, additional study of how audit firms had changed their actions because of BRA would allow for a more thorough analysis of the benefits and downfalls, as well as any conflicts.

It is important to examine the impact and aftermath of the implementation of BRA for auditing firms since any plan of action must consider the possible outcomes of its actual application. Curtis and Turley (2007) suggested that BRA did not necessarily benefit the client company. However, it is questionable whether an audit should ever result in any payoff for the client of an auditing firm; it could be argued that audits are intended to assist investors rather than companies whereby the payoff for investors is obtaining a complete picture of the risks associated with the companies in which they have invested (Flint et al., 2007). This is especially important for auditing firms which try to maximize their influence and importance in the financial world in order to demonstrate to customers that they can provide valuable services. However, Curtis and Turley (2007) showed that auditing firms would not always see increased value from BRA. On the other hand, there may be plenty of clients for whom BRA results only in finding that the company has not misstated anything materially in its financial reports and is operating truthfully and within the constraints imposed by both avoidable and unavoidable risks.

Knechel (2007) provided an analysis of the actual application of BRA as merely a means for auditing firms to gain related consulting and non-auditing business from existing clients. However, he added that, although it was likely that the auditing industry had implemented it for less than pure reasons, BRA had provided auditors with tools which could bring together many of the internal and external factors which worked together to create companies' financial reports. In fact, a positive result from the application of BRAG is the increased concern with business risks and various types of reporting strategies (Knechel, 2006). Auditing firms may seek to increase consulting fees by showing companies that they have the skills and knowledge to find and help alleviate business risks; looking for these risks can point out, also, areas of concern via the tests and controls needed to prevent material misstatements on financial reports.

Robson et al. (2007) seemed to concur with the notion that BRA was not created with the simple intention of being able to conduct more thorough or accurate audits. Instead, the methodology has improved understanding of the nature of clients' operations and the various opportunities which arise for materially misstated financial information. Lemon et al. (2000) 
explained the move to the BRA model in relation to gaining more consulting services through the provision of additional value-added services and results to clients. However, Lemon et al. (2000) added that, out of somewhat selfish motivations, the implementation of BRA may have improved functions for auditing firms in terms of finding potential material misstatements and other problems in companies' financial reports.

Overall, one of the literature's key findings is that BRA was implemented with the intent of requiring auditors to focus on the entire nature of a business and the full range of existing business risks. In this regard, auditors have had to change how they approach the audit process rather than focusing solely on financial statements. Auditors must examine a wide range of information which may never appear on a financial statement but which can indicate the current level of business risk.

\subsection{Motivation for Implementation}

Auditors regard part of this greater concern with BRA as a move to assure company stakeholders that material risks are not present (Koletar, 2003). This is not difficult to imagine in light of the recent worldwide accounting scandals. Shareholders want some assurance that they are being made aware of any actions being taken by a company which might result in future financial trouble. Fraser and Henry (2004) attempted to bring together the issues of business risk and audit risk with regard to the work performed by auditors. They explained that it was almost impossible to reconcile fully business risk and audit risk. In other words, auditors cannot identify all of the business risks present for a company; hence, there is no way to eliminate audit risk fully. This is because factors, such as the auditors' level of expertise and the amount of time available for contact with client firms, impact on auditors' abilities to identify all existing business risks.

Fazlollahi (2002) explained that BRA was taking precedence amongst auditors because it considered the financial, technical and managerial aspects of a business to be interconnected. Rather than focusing only on accounting functions or how transactions are reported, BRA is concerned with future risks and companies' risky behaviours. In addition, this form of auditing must seek to determine whether internal and external controls are present. A company may handle risk successfully from an internal level, but leave itself open to external risks such as risky investments, economic downturns, or litigation. If done properly, BRA should discover that these external risks are present are and not being controlled carefully. 
Lemon et al. (2000) noted that the emphasis of BRA differed from that of the traditional audit which sought only to examine financial statements for material misstatements. The authors explained that BRA moved toward an area in which auditors determined whether or not the actual objectives of the financial statements, as laid down by a company's management, were being met. Lemon et al. (2000) added that, in reality, companies might not understand fully this link between risk assessment and material misstatement of financial results. Companies may not understand why auditors are even trying to examine business risk and, furthermore, why, in their reports and dealings with the company's leadership, they are trying to explain various aspects of risk assessment. This may be an area of practice in which issues arise regarding the auditors' actual role and, if BRA is to be effective, may require the auditor to provide an explanation to the company's leadership.

With regard to the motivations for using BRA, the literature indicates that auditors are trying to assure companies and their stakeholders that they are able to identify all of the business risks present in a company's operations. Unfortunately, clients may not understand the auditors' motivation for gaining a full understanding of a company's business risks. Instead, clients may think that auditors are seeking too much information or simply wasting time and money.

\subsection{Advantages and Disadvantages of BRA}

Fraser and Henry (2004) explained that actually BRA might result in auditors overlooking business risks related to health and safety in relation to employees and the products or services being produced. This is because BRA focuses on business risks which are perceived to impact directly on an audit; consequently, issues of health and safety are viewed generally as secondary and are overlooked.

Certainly, BRA requires an evaluation of information which may have little or no direct link to that contained in a financial statement. Asking for information about company objectives, suppliers, partners, or even competitors may raise eyebrows amongst the company's leadership. Specifically, clients worry about the reasons why information not related entirely to financial statements is even necessary and how it is used (Knechel, 2007).

Literature on the advantages and disadvantages of BRA suggests that an important advantage of the methodology is that auditors must develop an in-depth knowledge of a client's business operations and activities. However, with all of the information which can be acquired 
using BRA, auditors are required to make more professional judgements about what is considered to be material for stakeholders and what is not. In this way, BRA can provide not only more indepth knowledge about a client but, also, can require a great deal of time for clients and auditors, and place added pressure on auditors to identify material information.

\subsection{Cultural Differences}

Previous research shows that global accounting and financial practices vary in relation to cultural attitudes (Gray, 1988). Culture impacts on a country's accounting standards because of the way in which people view individualism and power. Research demonstrates that countries which place importance on individualism, particularly within the financial industry, have a greater reliance on numerical statements. However, when compared to countries which are less individualistic in nature and which value power sharing they are, also, more likely to have greater errors in these statements (Chan et al., 2003). Interestingly, research shows that US accounting professionals tend to be more conservative in how they apply financial reporting rules (Tsakumis, 2007). Consequently, US accountants tend actually to provide more information in financial reports for fear of leaving out something which might later be considered to be a material misstatement of information.

Furthermore, Ding et al. (2005) found that, compared to existing laws, culture was actually more important in determining the actual auditing standards which were implemented. The researchers explained that cultural attitudes towards rules and standards of practice were often the most important variable in the standards which were put in place. They stated that cultural issues were likely to make very difficult any attempt to achieve a single global accounting and auditing standard. This relates less to concerns about technical issues of accounting standards and how they will impact on a country's financial community and more to cultural motivations and attitudes toward accounting standards. In the USA, the cultural attitude is that government supervision of the accounting industry is required because the private sector cannot regulate itself (Zeff, 2007). However, in the UK accounting and auditing industry, many have called actually for greater private-sector efforts to regulate the accounting industry and to ensure that shareholders and the public are protected (Zeff, 2007). In the USA, the general attitude is that personnel working in accounting cannot be trusted on their own, without government supervision. However, in the UK, 
there is an attitude that the accounting industry can regulate itself and that auditors and accountants can be trusted to generate the best outcomes for shareholders and the public.

Therefore, while there are similarities between the three countries about audits generally and BRA in particular, there are, also, important differences such as how to interact with clients and the reasons for adopting BRA.

\section{Research Questions}

This research is important because it provides new knowledge and fills the literature gap about the non-big-4 firms practices in auditing and, more specifically, in the area of BRA. Previously, little research was done to investigate the practices on non-big-4 firms. Clearly, the environment, in which the non-big-4 firms work, is different to the big-4 firms in terms of internal organization and clients' complexity. These require a different approach towards performing the engagement.

Previous research focused on the Big-4 implementation of the BRA; this research focuses on the non-big-4 auditors' attitudes towards the implementation of the BRA. This is an area that has not been researched before and, therefore, constitutes a gap in the auditing literature. Based on the information and literature, the researcher proposes several research questions in relation to the issues raised by the evolution of the auditing industry in the USA, UK and Canada, as well as concerns about BRA and the standards which govern how auditors do their jobs. The researcher's focus is on answering the following questions:

1 What are the motivations for adopting BRA?

2 What are the benefits and disadvantages of adopting BRA in terms of the audit process and risk concepts?

3 Regarding the aftermath of the adoption of BRA, does this new method improve the audit process? Is there a downside to BRA from the perspective of auditing?

These questions provide a means for understanding the nature of the industry as it now exists in relation to small and medium-sized firms as well as providing an understanding of any current evolution which may be taking place. Within the financial community, one of the concerns is that the 
motivation for adopting the business risk audit methodology was based solely on increased revenue and profits for major auditing firms. By asking auditors about their motivations and their firms' motivations for adopting this methodology, it is possible to understand actual working auditors' thoughts about the methodology and why it has gained so much popularity within the industry.

\section{Methodology}

This study combines qualitative and quantitative methods in order to obtain the data to address the research questions.

\subsection{Data Collection}

The researcher collected the data for this research in two parts: he collected preliminary quantitative data at an early stage in order to gain an initial idea about the subject. In the second part, he collected qualitative data by conducting 30 interviews with auditors; these comprise the main source of data for the research. The researcher believed that 30 interviews would provide enough information from which to determine similarities and differences across the three countries (USA, UK and Canada). The preliminary surveys provided initial information which the researcher used to construct the questions that formed the basis for the primary research interviews. The preliminary survey informed the construction of the primary research questions by obtaining insights from a relatively small sample of people within the auditing industries of the USA, UK, and Canada about their audit work and their perceptions and attitudes toward BRA. The reason for the researcher choosing these three countries was that their respective cultures had a large impact on the financial markets and the global economic system. The researcher used the data from the preliminary survey to refine and focus the primary research questions in order to provide more targeted results regarding the elements of BRA which were salient to the research participants. Thereby, the researcher enhanced the validity and reliability of the resulting conclusions and theory by ensuring that indeed the data-collection method was related to the issues and concerns of the auditors in the sample.

\subsection{Interviews}

The researchers carried out the face-to-face interviews at locations chosen by the participants in order to make them feel as comfortable as possible. For interviews carried out at the participants' 
workplaces, the researchers used a quiet place away from co-workers. The researchers conducted the telephone interviews after providing brief information about themselves and the purpose of the interview. The time taken to complete the interview was shorter than the face-to-face interviews which took 45 minutes to one hour. The average call lasted about 15 minutes, with some longer calls of about 30 minutes. During all calls, the researchers ensured that the participants answered all the questions.

The researchers audio taped all the interviews and, then, converted them to text. They collected more than 200 pages of text data, which created a large amount of data to be analyzed. The researchers entered the responses into NVivo 8.0 software which allowed a large amount of data to be catalogued and arranged according to the themes contained in the information, or according to specific categories. Also, the NVivo 8 software allowed the researchers to sort and analyze text files, quantitative data and interview transcripts. The researchers used, also, the NVivo 8 software to analyze the interviews in order to sort the responses according to specific participants, the questions asked and the participant's country. Once the data were sorted, the researchers analyzed the responses related to motivations for adopting the business risk audit methodology, an explanation of the advantages and disadvantages of BRA, and perceptions of the aftermath of the implementation of the business risk audit methodology. The researchers considered that the collected pieces of data were reliable since the majority of the participants were either partners or experienced managers in their firms. The participants provided precise information and answered clearly the questions asked.

Similar research on auditing used the interview method and open-ended questions (Buuren et at. 2014; Lemon et al. 2000). Marshall et al. (2013) recommended that 20-30 participants were an acceptable number in a qualitative research.

\subsection{Preliminary Questionnaire}

The preliminary data provided an overview regarding opinions and ideas from non-Big-4 firms in the UK, USA and Canada about BRA. Based on the preliminary data, it was possible for the 
researcher to construct a more specific interview instrument. For the preliminary survey, the researcher sent 86 emails to auditors in the UK, USA and Canada in order to obtain an idea of the percentage of responses. The auditors, who received the surveys, were selected at random from an internet search, based on their profile and location. The researcher received back e-mail responses from 40 participants.

The breakdown of participants from each of the three countries was almost exactly even, with 13 each from the USA and the UK, and 14 from Canada. In terms of positions within their firms, 29 of the participants were partners and 10 were managers. Only one participant was a senior auditor. In terms of firm size, the average staff number was 16-20 auditors, with an average of 1620 partners in the firm. The participants' average number of years of experience was 16-20.

When the researcher broke down the data from the preliminary surveys by country, the characteristics of the firms, which the participants work for, differed somewhat. For example, the UK firms had an average of one to five partners with 11-15 years' experience in the auditing industry. Of the $13 \mathrm{UK}$ participants, eight were partners, four were managers and one was a senior auditor; finally, most of the UK firms had more than 25 employees. The US firms had 1-10 partners and, on average, 21-25 employees; the participants had 11-15 years' experience. Of the 13 US participants, 10 were partners whilst three were managers. Finally, the Canadian participants worked in firms with 6-10 partners, and had 6-15 years' experience. Generally, their firms had 11-15 employees. Ten of the Canadian participants were partners, whilst three were managers. Figure 1 shows the demographic information from the preliminary data collection.

Figure 1: Demographics from Preliminary Data Collection 


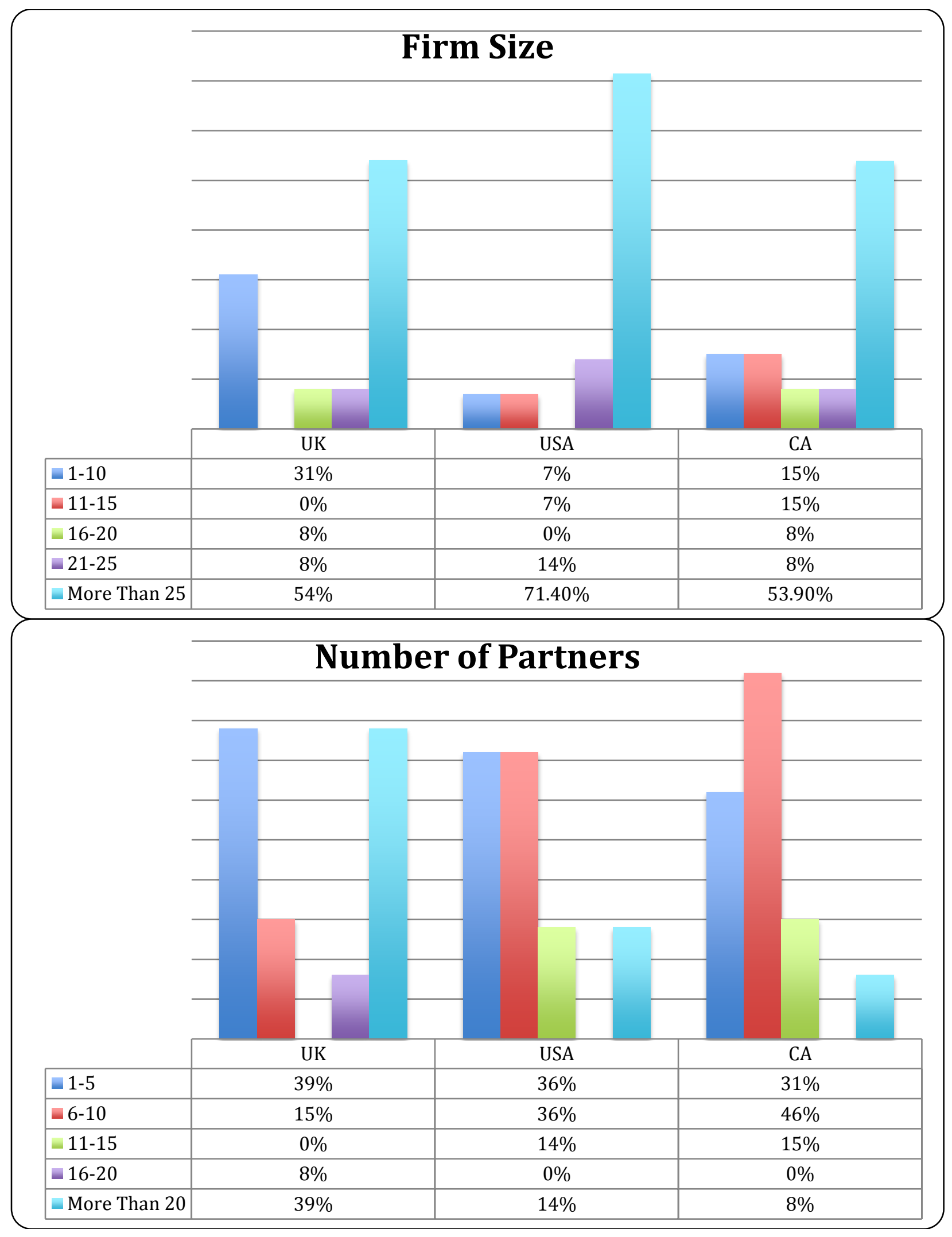




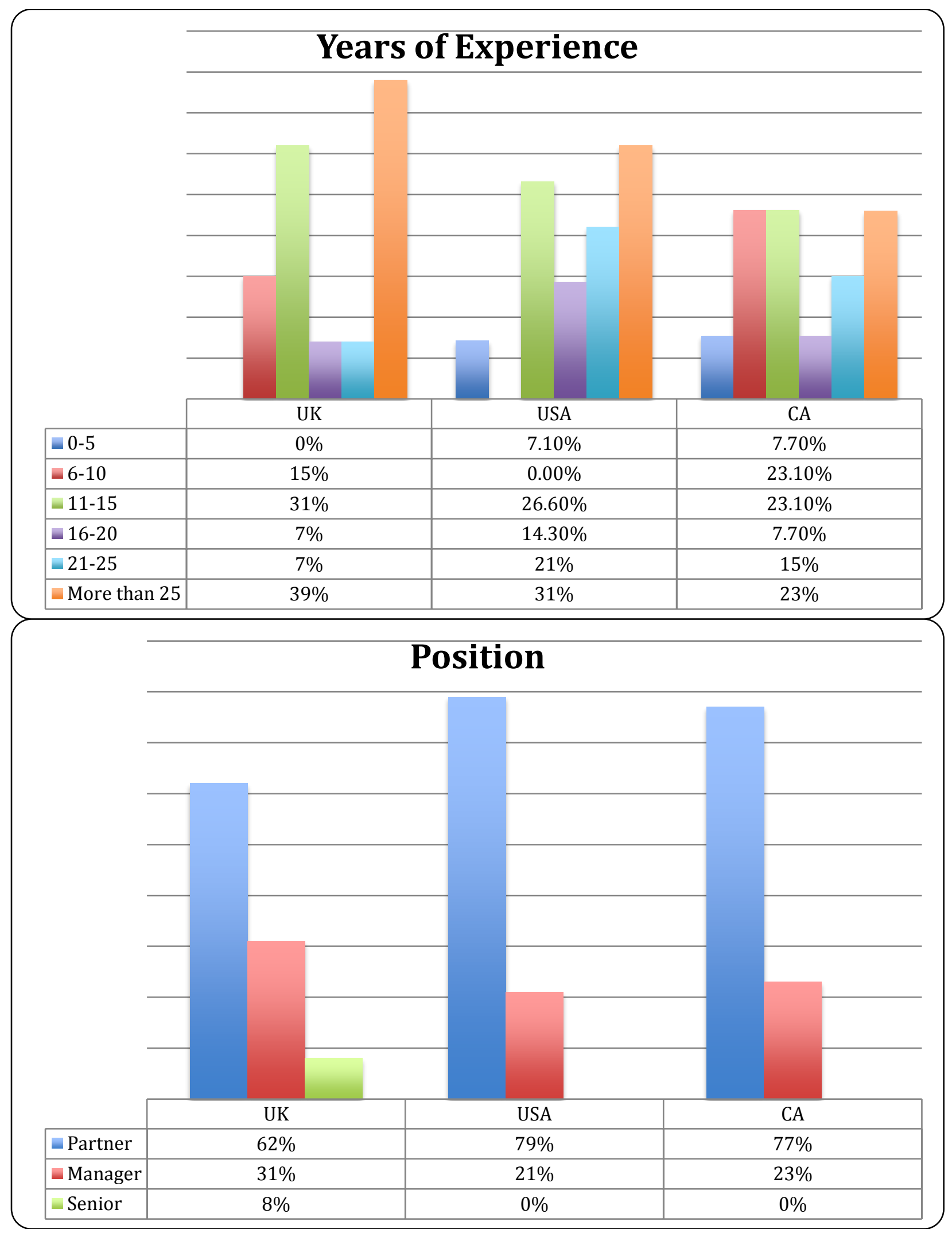




\subsection{Primary Interviews}

For the primary data collection, the researcher asked each individual from the preliminary survey to participate in a more in-depth interview. The researcher informed the participants that the aim of the in-depth interviews was to understand some of the issues about BRA which had emerged from the results of the preliminary survey. It should be noted that the findings from the preliminary survey did not change any of the research questions. In total, 31 of the 40 participants from the preliminary survey agreed to participate in the primary data-collection interviews.

\section{Findings}

\subsection{Motivation for adopting BRA}

The first research question asked about the auditors' motivations for adopting BRA. The responses, provided by the Canadian participants, suggested that their motivation was the general momentum within the audit industry to adopt BRA. For example, several auditors pointed either directly or indirectly to the risk that auditing firms faced in light of recent accounting scandals which had affected major companies like Enron. One of the participants stated that his firm's partners were motivated to minimize risk when conducting audits. Although BRA existed before any recent accounting scandals, these events remained relevant and resulted in many of the participants thinking about BRA in terms of themselves. Although many of them did not use BRA before the accounting scandals, once the scandals came to public attention, there was a feeling that BRA ought to be used to minimize risk.

In addition, almost all Canadian participants stated that their motivation to adopt BRA was because there was a requirement to do so in Canada. Specifically, the Canadian Institute of Chartered Accountants Handbook, Section 5150 and ISA 300, "Planning an Audit of Financial Statement", refers to methodologies which are part of BRA. However, some Canadian participants stated that changes in auditing requirements were not the only reason for adopting BRA. They stated that the industry was moving towards BRA and that they wanted to stay current with developments.

Interestingly, two Canadian participants alluded to financial gain as a motivation for their firms to adopt BRA. One of the participants stated directly that the partners in his firm were motivated by making money, and this was part of the reason for offering BRA to clients. Extra 
revenue would be earned because additional consulting services could be provided in order to help clients to understand the BRA process and to advise them of how to deal with the identified risks. Another Canadian participant explained that his firm's partners believed BRA would reduce the overall costs of audits for their clients because the audits would be more focused and involve less time obtaining information which might not be relevant to the identified risks. Furthermore, the entire process allows for some functions to be moved to a time of year when the firm is less busy.

In contrast to the Canadian participants, the UK participants discussed the need to remain compliant with national or international accounting standards. As in Canada, UK financial regulators and organizations, which set auditing standards, had adopted concepts of BRA and stated that auditors ought to be using this approach (Robson et al., 2007). Several UK participants explained that changes in regulations were forcing them to adopt BRA. Two participants explained, also, that the general trend on the part of the International Accounting Standards Board was to adopt more of a BRA approach and, therefore, it had become necessary to adopt BRA.

The Big-4 firms began to adopt BRA on a widespread basis in the late 1990s and into the 2000s. The full adoption of BRA became evident by the Big-4 firms as they published working papers and explanations of how they used BRA in practice (Robson et al., 2007). KMPG's 1997 publication provides a good explanation of the company's use of BRA (Bell et al., 1997). One participant, who explained that his firm was not trying to compete with the Big-4 because his firm's desired clients were smaller companies, stated that the firm had adopted something of a scaled-down approach to BRA in order to be more responsive to client needs.

For the US auditors, one of the respondents highlighted what he viewed as something of a dual purpose for using BRA in terms of being more efficient and doing more planning. Another US auditor explained that he had been using BRA already before auditing standards organizations began to inform members to adopt greater use of the methodology. However, he explained that BRA was actually more efficient because it allowed for an examination of the company, followed by an examination of the company's environment in order to determine where additional risk might exist. In essence, some US auditors viewed BRA as improving audit efficiency. On the other hand, one of the US auditors stated not only that the motivation for adopting BRA was because of changes in professional standards related to the rules implemented by accounting standards organizations, but, also, blamed the changes in standards on the Big-4. 
With regard to the information provided about the motivations for adopting BRA among SMEs in the UK, USA and Canada, there was some agreement that BRA provided a more thorough way to conduct audits. Even participants, who explained that their firms had used some form of BRA previously, stated that the new regulations and standards provided more structure in how BRA was used. This might indicate that even if some participants were motivated solely to ensure compliance with changing standards, there was some recognition that the changes might be positive in terms of how they conducted their businesses.

\subsection{Advantages of BRA}

The Canadian participants seemed to have varying views about the advantages of adopting BRA. Some participants explained in detail how BRA made them more aware of problems and concerns with their clients. However, other participants stated clearly that the only advantage of adopting BRA was a reduction in audit risk for themselves and their firms. Another respondent stated that, because of BRA, his firm was putting much more planning in place before conducting audits. Rather than simply jumping into the auditing process or using an informal methodology for conducting risk audits, the advantage of BRA is that a specific set of guidelines must be followed and documented in order to meet regulatory guidelines (SAS 109; CAS 315; ISA 315).

One Canadian participant explained the advantages of BRA in light of client interaction. He stated that clients were concerned initially about the type and amount of information being collected but eventually were able to understand the work going into the audit, and the way in which risk was identified. Importantly, this auditor mentioned specifically business risk and the ability to better identify it; this related, also, to reductions in audit risk.

The UK participants appeared to have a very different idea about the advantages of BRA. Many stated that the advantage of BRA was being able to identify more easily key areas of a client's operation requiring investigation and examination. With specific regard to small and medium-sized auditing firms, one of the participants explained that, even for firms of this size, BRA allowed people to know that a standard process or methodology was being followed. Another participant explained that BRA allowed firms to help clients to plan for the future by moving beyond simply looking at what was occurring currently, and towards future goals and objectives through identifying risk. This participant explained, also, that because clients knew that auditors were looking for risks, clients themselves were doing a better job of finding and preventing risk 
before the audits occurred. Another UK participant considered that an advantage of BRA was that it was ongoing, as opposed to a yearly task. The improved level of documentation and client understanding means that the task of identifying risk becomes a normal part of clients' operations.

Interestingly, although the UK auditors did discuss the advantages of BRA to the firm, they focused more heavily on the advantages to clients in terms of the ability to determine areas in which greater risk existed and to provide more information to clients in this regard.

In addition, several participants used specifically the term "communicating" when talking about the changes in relationships between firms and clients. Correspondingly, BRA requires more communication and explanation in terms of what audit firms provide to clients and what clients can expect regarding information and documentation. Again, the focus seems to be on the benefits to the clients.

The US participants focused almost exclusively on the benefits of BRA to the auditing firm (Knechel, 2006; Lemon et al., 2000). For example, one US participant explained the benefit of BRA in relation to the involvement of upper management, such as senior managers and partners, in the audit process. The US participants focused also on advantages relating to their own knowledge and level of planning before conducting audits (SAS 300). They discussed feeling more knowledgeable going into an audit and being more prepared when talking to clients and examining the environment in which clients operated. Furthermore, being able to perform an audit in less time helped to avoid wasting the client's time. Correspondingly, this allows clients to save money. Another US participant mentioned the shorter amount of time required to conduct a BRA, as opposed to other audit methodologies. However, this was not with reference to economic advantages for auditing firms, but rather to auditors being able to use intellect and focus on understanding the client which, in turn, reduces the amount of time spent on fieldwork.

Responses from all three countries regarding the advantages of BRA showed clearly a difference in attitudes between SMEs in Canada and the UK when compared to the USA. The UK and Canadian participants from the stated that they performed better because of the reduction in audit risk caused by more thorough audits which examined the full range of business risk to clients. However, they stated, also, that they were better able to understand their clients and to provide information which resulted in firms making more of an effort to reduce risk. However, the US participants seemed to focus heavily on what BRA has done for them and their auditing firms there appeared to be little recognition of possible advantages to clients from BRA. Even with 
regard to gaining a better understanding of their clients through BRA, the participants referred either to benefits for the firm or the reduced amount of time needed to conduct fieldwork for an audit.

\subsection{Disadvantages of BRA}

Whilst the USA participants focused on the possible economic savings resulting from BRA, it is interesting to note that many of the Canadian participants explained that the disadvantage of BRA was the cost which it entailed for clients. Several UK participants explained that BRA was designed more for large companies; for smaller companies, the detailed work required through BRA meant greater expense which might be unnecessary. Several Canadian participants raised the effect of BRA on small firms not only in terms of wasted time and money but, also, with regard to the focus on the balance sheet and financial reports - rather than the hidden risks in operations or business environments - and the in-depth BRA documentation, which, in reality, did not provide added value for the client.

The general focus of the UK and Canadian participants seemed to be on concern for clients and the impact that BRA had on them; even when phrased in relation to the auditing firms; the concern seemed to be more for the clients who were affected ultimately.

These differences between the UK and Canadian auditors, and those in the USA, are unsurprising given the information about differences in cultural attitudes. US auditors and accountants tend to be more individualistic in nature and dislike the idea of being watched while doing their jobs (Chan et al., 2003).

Here, what is perhaps most important is that there is an indication of the auditors' general dislike for the changes which have occurred within the industry in relation to the accounting scandals in the USA. One participant explained that he did not know the clients any better now than he did under previous auditing standards. This view was shared by another US participant who stated that the process, used to conduct audits before BRA, was better than what was used currently. As noted in the literature review, previous studies noted that BRA could cause auditors to overlook information and to avoid doing all the necessary work in order to identify material misstatements on the part of clients (Srivastava and Mock, 2002; Houston et al., 1999). One participant stated that looking for risks was something that was done always; consequently, the move to BRA did not change anything for auditors. 
Another participant explained also that, especially in relation to smaller clients, the issue of risk had been addressed at all times. He stated that auditors had talked always to their clients about ways in which to reduce any existing risks. Here, aside from the direct sentiment, there seems to be an underlying feeling that BRA has been adopted widely only because of public concerns resulting from accounting scandals and not because of any real need for changes in how audits are performed. This is noteworthy because it mirrors some of the issues discussed by the UK and Canadian auditors.

One US participant explained that, especially for auditors who have been in the business for 20 years, the learning curve, required to fully use the concepts behind BRA, was a disadvantage to adopting the approach (Khalifa et al., 2007). However, the participant stated that this problem was unlikely to persist.

The US auditors seemed to focus only on their own concerns and those of their firms with regard to the disadvantages of BRA. Although this was combined with a comment about the negative impact on the auditing firm, only one US participant mentioned any disadvantages to clients. This is important in terms of understanding the priorities of US auditors with regard to BRA and its implementation. There was more concern about the firms being able to save money and time than about what clients faced, especially amongst clients who might not receive any additional benefit from BRA (Khalifa et al., 2007).

\subsection{Aftermath of BRA}

The final issue is how the aftermath of BRA implementation was identified and, in particular, whether additional changes are needed or whether any drawbacks. Here, "Aftermath" means the results and implications noted after using BRA; whether auditing firms considered either moving away from the method or like it and want to continue its use. The Canadian participants highlighted a need for changes to make the process more efficient and less complicated. However, it is interesting that, even in light of these comments, none of them expressed a need to abandon BRA fully. In fact, a small number of participants stated directly that no deviation from BRA ought to be made. The expressed opinions were that BRA had improved the overall audit approach because auditors were more focused on finding business risks in their clients' firms, and on documenting their findings and justifying their professional judgements. 
It is noteworthy that one Canadian participant viewed the BRA aftermath as just one part of the auditing industry's history, in which changes have constantly been made and are likely to continue, even to the point of actually reducing the requirements that now exist within BRA. This is because of the industry's belief that BRA entails too many rules for auditors and too many requirements regarding the information which must be examined during the audit process. The Canadian participants agreed generally that BRA ought not to be abandoned but that reductions might be needed either in the number of details collected during an audit, or the level of required documentation.

As in other areas of examination in this research, the UK auditors' responses, , were very similar to those provided by the Canadian auditors. The general UK consensus was that BRA was a good thing but that changes might be needed regarding how it was used within small companies. Other participants expressed similarly that BRA provided more advantages than disadvantages; however, changes were needed to account for the fact that SMEs differed from large companies and had separate sets of issues which had to be audited with regard to risk. Furthermore, it was expressed that BRA was needed not only for the sake of working more closely with clients but, also, to provide something more for clients than simply looking at previous financial statements to ensure that they were materially correct. The opinions, provided by the US auditors might be most surprising, given the differences in opinion in other areas between the US auditors and those in Canada and the UK. Overall, the US auditors agreed with those in Canada and the UK that abandoning BRA was unnecessary. Instead, changes are needed to make the process more effective and efficient for companies. One of the US participants stated that after a difficult first year of using BRA, the process becomes easier and more efficient.

Despite the similarities in responses from US auditors compared with those from Canada and the UK, there is one important difference. One US participant explained that he would give up BRA because the old standards were better. Another explained that the only reason to abandon BRA was the amount of work involved and that using BRA fully meant performing double the work in some areas. It seems as though there is a greater level of concern about auditors having to use audit methodologies which may not be truly beneficial to clients, especially SME clients (Robson et al., 2007; Khalifa et al., 2007). In addition, the auditors from Canada and the UK seemed to accept the fact that, because of accounting scandals, BRA had become popular and entrenched regulatory policy (Knechel, 2006). 
Table 1 presents a summary of the data obtained from the auditors across all three countries with regard to their attitudes about BRA in terms of advantages, disadvantages, motivation for adopting, aftermath, and impact on risk.

Table 1: Summary of Findings

\begin{tabular}{|c|c|c|c|c|c|}
\hline & Advantages & Disadvantages & Motivation & Aftermath & Risk \\
\hline Canada & $\begin{array}{l}\text { - Conduct } \\
\text { better audits } \\
\text { - Reduce risk } \\
\text { to the firm }\end{array}$ & $\begin{array}{l}\text { - Increased } \\
\text { cost of audits } \\
\text { for clients } \\
\text { - Burden for } \\
\text { small } \\
\text { companies }\end{array}$ & $\begin{array}{l}\text { - Following } \\
\text { general trend } \\
\text { within the } \\
\text { industry } \\
\text { - Increase } \\
\text { revenues by } \\
\text { meeting } \\
\text { customer } \\
\text { demands }\end{array}$ & $\begin{array}{l}\text { - Some } \\
\text { changes } \\
\text { needed to } \\
\text { BRA }\end{array}$ & $\begin{array}{l}\text { - Lower level } \\
\text { of risk to } \\
\text { firms and } \\
\text { clients }\end{array}$ \\
\hline UK & $\begin{array}{l}\text { - Conduct } \\
\text { better audits }\end{array}$ & $\begin{array}{l}\text { - Increased } \\
\text { cost of audits } \\
\text { for clients } \\
\text { - Burden for } \\
\text { small } \\
\text { companies }\end{array}$ & $\begin{array}{l}\text { - Comply } \\
\text { with national } \\
\text { and } \\
\text { international } \\
\text { accounting } \\
\text { standards } \\
\text { - Ability to } \\
\text { compete } \\
\text { with larger } \\
\text { firms }\end{array}$ & $\begin{array}{l}\text { - Some } \\
\text { changes } \\
\text { needed to } \\
\text { BRA }\end{array}$ & $\begin{array}{l}\text { - Lower level } \\
\text { of risk to } \\
\text { firms and } \\
\text { clients }\end{array}$ \\
\hline USA & $\begin{array}{ll}\text { - Benefits } \\
\text { firms } \\
\text { because of } \\
\text { efficient } \\
\text { work } \\
\text { audits }\end{array}$ & $\begin{array}{l}\text { - Increased } \\
\text { cost for } \\
\text { auditing } \\
\text { firms } \\
\text { - Greater } \\
\text { level of } \\
\text { supervision } \\
\text { required for } \\
\text { lower-level } \\
\text { auditors }\end{array}$ & $\begin{array}{l}\text { - Follow } \\
\text { general } \\
\text { industry } \\
\text { trend } \\
\text { - Increase } \\
\text { efficiency }\end{array}$ & $\begin{array}{l}\text { - Some } \\
\text { changes } \\
\text { needed to } \\
\text { BRA }\end{array}$ & $\begin{array}{l}\text { - Lower level } \\
\text { of risk to } \\
\text { firms and } \\
\text { clients }\end{array}$ \\
\hline
\end{tabular}

\section{Discussion}

With regard to the motivations for adopting, the advantages and disadvantages, and the aftermath of BRA for auditors in the UK, USA and Canada, this investigation reveals important differences 
between the three countries. In all the examined areas, the UK and Canadian participants had similar attitudes and their concerns were based largely on how BRA affected audit clients. However, the USA participants focused more on how BRA had affected them and their firms. Even when the UK and Canadian participants talked about their motivation for adopting BRA in relation to changes in regulations, they mentioned still their clients' desires to have access to BRA. However, the USA participants took a different tone regarding the changes in audit regulations which, essentially, forced them to adopt BRA. They expressed a lack of desire to adopt BRA and, also, named recent accounting scandals as a larger motivation for changes to the way in which audits were conducted.

Curtis and Turley (2006) questioned whether BRA was indeed effective in relation to the amount of time required to conduct audits. Their findings show that, given that there is no guarantee of finding more errors or preventing material risks, some of the concern over the added costs to auditing firms, especially those in the USA, may be warranted,. However, it was noted, also, that BRA could help to overcome some of the complacency which led to scandals such as Enron and WorldCom (Knechel, 2007). Furthermore, differences in opinion about the advantages and disadvantages, and even motivations for adopting BRA, must be understood separately from any past events. Instead, they should be analysed in relation to auditors' duties and whether or not BRA yields more efficient and better audits.

Even comments, related to whether or not BRA should be abandoned, differed in terms of concerns about clients versus concerns about auditors and their firms. The UK and Canadian auditors talked about a partial revision of BRA in order to better focus on SME clients and the ability to tailor audits to the client's industry. None of the UK or Canadian auditors suggested retreating completely from BRA and returning to an older audit methodology. However, some USA participants expressed the view that BRA ought to be abolished because it was a more stringent version of previous approaches. Indeed, it may be that, compared to the Big-4 USA firms indeed, small and medium-sized US auditing firms have been using BRA and are more aware of their clients' risk concerns and issues.

\section{Conclusion}

With regard to BRA, this research aimed to identify the attitudes and behaviours of auditors working for small and medium-sized auditing firms in the UK, USA and Canada. This 
investigation was guided by three research questions on the motivations of auditing firms to adopt BRA; the benefits and disadvantages of it; and the BRA aftermath.

The Canadian and UK respondents focused largely on the advantages of BRA in terms of benefits to their clients. Even the Canadian respondents, who explained that the level of risk for auditing firms was reduced, related this to the performance of a higher quality audit. In terms of the disadvantages, the Canadian respondents stated that BRA increased costs for clients because of the necessary extra work and added to the burden on small companies because, in BRA, many of the areas of focus were unnecessary for small firms. The UK respondents gave nearly the same responses, highlighting the disadvantages of BRA in terms of the added costs to clients and the burden placed on small businesses due to guidelines and regulations on how BRA ought to be conducted. The USA respondents remained focused on disadvantages for their firms and explained that, although BRA improved audit efficiency, there were added costs to firms because of the strict requirements which had to be followed, and the required increased interaction between firms and clients. The US auditors explained, also, that BRA required greater supervision from managers and partners of auditing firms over the work of lower-level auditors.

Responses about motivations for adopting BRA were somewhat similar across all three countries. The Canadian participants were motivated by following the general trend of using BRA within the auditing industry. They highlighted, also, increased revenue from clients due to more customers demanding that BRA be performed. The UK participants concurred in terms of complying with standards which focused more on BRAs and competition within the industry in meeting clients' demands for BRA.

Unlike their responses on the advantages and disadvantages of using BRA, the US participants' responses about motivations in terms of following the industry's general trend were almost identical to those of the UK and Canadian participants. However, another cited motivation was increasing the efficiency of audits.

The researcher asked the auditors, also, about the aftermath of using BRA. Respondents from all three countries stated that BRA ought not to be abandoned completely. They considered that BRA offered many benefits which improved audits for clients and auditing firms. However, especially when conducting audits of SMEs which do not have the same risk level as large corporations, some changes are needed in order to increase flexibility for auditors. 
Finally, the participants raised the issue of risk in relation to conducting BRA. Overall, the participants from the UK, USA and Canada explained that BRA reduced the risk to both themselves and their clients. The participants explained that BRA required a more thorough knowledge of their clients and their clients' actions and their future plans; this knowledge could be used to better identify material risks which might impact negatively on clients.

The results provide room for discussion about their implications with regard to the auditing industry and use of BRA. One implication is that auditors seem to have conflicting opinions about the usefulness of BRA. The participants expressed at least some irritation with BRA because of the strict guidelines involved. However, they stated that BRA reduced the risk of not identifying material risks in their clients' operations and actions. This concurs with findings from previous studies (Robson et al., 2007; Johnstone, 2000; Bell et al., 1997; Eilifsen et al., 2001).

Another implication is that, compared to those in the USA, there seems to be a clear difference in the attitudes and areas of focus between UK and Canadian auditors. Many of the attitudes, expressed by the UK and Canadian auditors, showed a customer-centred focus on how BRA had affected the auditing industry and their customers in terms of costs and burden. However, the US auditors focused more on the burdens and costs which BRA had created for them and their firms. The problems brought about by BRA for customers were secondary to the concerns facing the auditors.

This suggests that in contrast to the beliefs of US auditors, there are cultural differences in how auditors in the UK and Canada think of themselves and their duties to the financial industry. The implication seems to be that UK and Canadian auditors view themselves as having a duty to maintain honesty and transparency within the financial industry. While it is likely that USA auditors hold this view too, the findings suggest that there are, also, strong concerns about their own work and their abilities to generate revenue. This may indicate that USA auditors are much more focused on profits and revenue and less focused on the concerns of clients. From the standpoint of auditing and culture, these findings show the impact which culture and auditing standards can have on each other. The standards and practices of auditing firms do not exist in a vacuum; instead, larger cultural issues impact on the implementation of the auditing standards and the way in which auditors view them (Chan et al., 2003; Tsakumis, 2007; Gray, 1988).

The results are important not only in relation to small and medium sized audit firms in the USA, UK, and Canada but, also, because they allow for a comparison with results of previous 
studies involving Big-4 audit firms and BRA. Extant studies concluded that the use of BRA in Big-4 firms resulted in a broader consideration of clients' business risks (Lemon et al., 2004). In this research, many of the participants stated that BRA allowed for a greater focus on broader issues and concerns within an organization which might contribute to overall business risk. Andersen (2006) stated that Big-4 firms used somewhat more complex procedures than those used by other firms; this is unsurprising when the firm is focusing on broader issues. This research's participants stated, also, that, whilst BRA was generally helpful, it would benefit from adjustment, particularly for use with smaller clients. This view concurs with previous research conducted with auditors working for Big-4 firms (Lemon et al., 2004). Interestingly, the types of changes, suggested to improve BRA for use amongst Big-4 firms, are an expansion and broadening of the business-risk focus. In comparison, the ideas, related to adjustment amongst the participants in this research, seem to suggest that BRA needs to be adjusted to allow for a reduction in the types of business risk which are of concern. This is because of the more specific business risks related to SMEs.

One hypothesis as to the divergence, in the perception of whether BRA should be narrowed or broadened in relation to how business risks among clients are evaluated, may be a function of the size of the clients. Small and medium-sized audit firms are more likely to have smaller clients and, applying Andersen's (2006) theory should require less complex procedures. Therefore, these firms may perceive BRA as being too broad or complex. In contrast, auditors, working for Big-4 firms, are more likely to work with larger clients in which a much greater set of business risks may be present and, thus, require more complex procedures within BRA.

The importance of this research is its contribution to the literature of non-big-4 practices in UK, USA and Canada. Also, it opens the door for more research to be done in other countries. In addition, by showing how that size and complexity of SMP clients are different from the big clients, it assists those countries' standards setters to better understand the thinking of non-big-4 auditors and their needs.

The nature of the qualitative research limited our sample size and this should be taken into consideration when implementing this research's findings, however, the pieces of data, which the researcher collected from the sample, were of high quality information and were used properly to address the questions on the research. 
One driver of this research was to compare the ideas and attitudes held by auditors in the UK, USA and Canada. Additional research is needed to examine fully the existing differences between auditors in these three countries. Future studies could broaden the scope of the research from a single methodology, such as BRA, and ask auditors in all three countries about a variety of current issues affecting the auditing industry. For example, UK, US and Canadian auditors could be asked what they think about audit methodologies in an environment in which a move towards global auditing and accounting standards is being pursued. The participants could be asked about their opinions on whether or not BRA could be beneficial in other countries and, also if global auditing standards are achieved, whether or not they think BRA will continue to be used in the future. Further research would provide, also, valuable practical information for regulatory agencies and the academic community about real-world concerns and issues which, based on the size of their firms, are important to auditors. Rather than discussing auditors' attitudes and ideas solely based on theories, this research would bridge the gap between theory and real-world attitudes and actions. 


\section{References}

Abdel-Khalik, A.R. (1998), The Blackwell Encyclopaedia Dictionary of Accounting, Blackwell Publishing, New York.

Andersen, T.J. (2006), Perspectives on Strategic Risk Management, Copenhagen Business School Press, Copenhagen.

Ball, R. (2006), "International financial reporting standards (IFRS): pros and cons for investors", Accounting and Business Research, Accounting Policy Forum, 5-27.

Bell, T.B. and Solomon, I. (2002), Cases in Strategic-Systems Auditing: KPMG and University of Illinois at Urbana-Champain Business Measurement Case Development and Research Program, KPMG, Montvale, NJ.

Bell, T.B.; Marrs, F.O.; Solomon, I. and Thomas, I. (1997), Auditing Organizations through a Strategic Systems Lens, KPMG, Montvale, NJ.

Buuren, J.; Koh, C.; Amerongen, N. and Wright, A. (2014) "The Use of Business Risk Audit Perspectives by Non-Big 4 Audit Firms", Auditing: A Journal of Practice \& Theory, Vol. 33 No. 3, pp. 105-128.

Brands, K. (1998), "KPMG Peat Marwick's business measurement process-implementing change", Management Accounting, Vol. 79 No. 7, p. 72.

Campbell, D. (2008), International Securities Law and Regulation, Lulu, New York.

Canadian Institute of Chartered Accountants (2005), "Planning and supervision International Standards on Auditing 300",Canadian Institute of Chartered Accountants Handbook, International Auditing and Assurance Standards Board, London, section 5150.

Chan, K.H.; Lin, K.Z. and Mo, P.L.L. (2003), "An empirical study on the impact of culture on audit-detected accounting errors", Auditing, Vol. 22 No. 2, pp. 281-295.

Curtis, E. and Turley, S. (2007), "The business risk audit - a longitudinal case study of an audit engagement", Accounting, Organizations and Society, Vol. 32, May, pp. 439-461.

Ding, Y.; Jeanjean, T. and Stolowy, H. (2005), "Why do national GAAP differ from IAS? The role of culture", The International Journal of Accounting, Vol. 40, pp. 325-350.

Eilifsen, A.; Knechel, R.W. and Wallage, P. (2001), "Application of the business risk audit model: a field study”, Accounting Horizons, Vol. 15 No. 3, pp. 193-207.

Elliott, R. (1996), “Auditing reborn”, CA Magazine, August, pp. 36-38.

Fazlollahi, B. (2002), Strategies for E-Commerce Success, Idea Group, New York.

Fraser, I.A.M. and Henry, W.M. (2004), "Better off apart?" Internal Auditing and Business Risk, January, pp. 26-28.

Flint, C.; Fraser, I.A.M. and Hatherly, D.J. (2007), "Business risk auditing: a regressive evolution?" Accounting Forum, Vol. 32 No. 2, pp. 143-147.

Gray, S.J. (1988), "Towards a theory of cultural influence on the development of accounting systems internationally", ABACUS, Vol. 24, pp. 1-15.

Houston, R.; Peters, M. and Pratt, J., (1999), "The audit risk model, business risk and auditplanning decisions", The Accounting Review, Vol. 74 No. 3, pp.281-298.

Johnstone, K.M. (2000), "Client-acceptance decisions: simultaneous effects of client business risk, audit risk, auditor business risk, and risk adaptation", Auditing, Vol. 19 No. 1, pp. 1-25.

Khalifa, R.; Sharma, N.; Humphery, C. and Robson, K. (2007), "Discourse and audit change: transformations in methodology in the professional audit filed", Accounting, Auditing and Accountability Journal, Vol. 20, July, pp. 825-854.

Knechel, R. (2001), Auditing: assurance and risk, (2ndedition), Southwestern Publishing Company, Cincinnati, $\mathrm{OH}$. 
Knechel, R. (2007), "The business risk audit: origins, obstacles and opportunities", Accounting, Organizations and Society, Vol. 32, May, pp. 383-408.

Koletar, J. W. (2003), Fraud Exposed: What you Don't Know Could Cost Your Company Millions, John Wiley and Sons, New York.

Lemon, W. M., Tatum, K.W. and Turley, W.S. (2000), Developments in the Audit Methodologies of Large Auditing Firms, ABG Publications, London.

Marshall, B.; Cardon, P.; Poddar, A. and Fontenot, R. (2013), "Does Sample Size Matter in

Qualitative Research?: A Review of Qualitative Interviews in is Research", Journal of Computer Information Systems, Vol. 54 No. 1, pp 11-22.

Robson, K.; Humphery, C.; Khalifa, R. and Jones, J. (2007), "Transforming audit technologies: business risk audit methodologies and the audit field", Accounting, Organizations and Society, Vol. 32, May, pp. 409-438.

Srivastava, R.P. and Mock, T.J. (2002), Belief Functions in Business Decisions, Springer, London.

Tsakumis, G.T. (2007), "The influence of culture on accountants' application of financial reporting rules", ABACUS, Vol. 43 No. 1, pp. 27-48.

Winograd, B.N.; Gerson, J.S. and Berlin, B.L. (2000), "Audit practices of PricewaterhouseCoopers", Auditing: A Journal of Practice and Theory, Vol. 19 No. 2, pp. 175-182.

Zeff, S.A. (2007), "Some obstacles to global financial reporting comparability and convergence at a high level of quality", The British Accounting Review, Vol. 39, pp. 290-302. 